\title{
Lack of consideration for end-users during the design of agronomic models. A review
}

\author{
Lorène Prost • Marianne Cerf • Marie-Hélène Jeuffroy
}

Accepted: 12 August 2011 / Published online: 14 October 2011

(C) INRA and Springer-Verlag, France 2011

\begin{abstract}
Agriculture should now provide not only high yields but also sustainable development with a sound management of the diversity of ecosystems. Due to this increased complexity of objectives, models have recently become major tools that can integrate several parameters. Failure to apply models outside research is however a major issue. Here, to identify the precise grounds of this failure, we analyzed what models are intended for by scientists during their design. We performed a literature analysis on agronomic modelling practices. Specifically, we analyzed 518 scientific article abstracts reporting either new models or improved existing models. Articles were published in eight mainstream agronomy journals over a 10 -year period. We also analyzed 25 full-text contents randomly selected from the initial dataset. In order to assess how models match the uses they are intended for, we first analyzed the design methodology used to build models. Second, we studied how authors defined the potential use of models by analyzing both the claimed objectives and references to model use and users. We then compared our findings on design methodology with our findings on intended use. Our results first show that the design methodology for modelling is presented as a segmented and standardized process. Each article refers to one or more of the following six steps to describe the design process for modelling: (1) description
\end{abstract}

\footnotetext{
L. Prost $(\bowtie) \cdot$ M. Cerf

INRA UR 1326 SenS,

F-78850, Thiverval-Grignon, France

e-mail: prost@grignon.inra.fr

M.-H. Jeuffroy

INRA UMR 211 Agronomie,

F-78850, Thiverval-Grignon, France
}

of the model structure, inputs, outputs and validity domain, (2) description of the data used to build the model, (3) model formalism, (4) calibration parameterisation, (5) validation, and (6) application. We found that information about the design process like iterations, errors, improvements is never emphasized in the abstracts, whereas this information is sometimes quoted in the full-text contents. This finding demonstrates that the design methodology for modelling is not addressed as a research topic. Second, we show that whereas $88.8 \%$ of authors claim in their abstracts that the major objective of their models is to improve understanding as opposed to support action, $19.5 \%$ of authors also quote a possible use of their models outside research. The initial objective of understanding is thus extended to use the models as tools for action. Overall, we conclude that the agricultural research community is not highly concerned by the effects of the design methodology on the suitability of the model structure and on potential applications. Moreover, although the six steps of the design process may be appropriate for designing models devoted to improve understanding, no specific methods are proposed to design models for action. We did not find evidence that the modellers connect the design of the model with its use by end-users. We suggest that this issue could be solved by developing participatory methodology design involving end-users in model design.

Keywords Model $\cdot$ Modelling $\cdot$ Use $\cdot$ Design $\cdot$ Method Methodology $\cdot$ Agronomy $\cdot$ Agronomic modelling practices

Contents

1. Introduction

2. Materials and methods 2.1. Analyzing abstracts and full texts 2.2. Building of the dataset 
2.3. Work on the 518-unit dataset of abstracts

2.4 Analyzing full texts in a randomized sample of 25 papers

3. Results and discussion

3.1. Describing elements in the 518-unit dataset

3.2. A six-step design methodology shared by the agronomic research community

3.2.1. The design methodology as described in the abstracts

3.2.2. Additional findings from the full-text analysis

3.2.3. Conclusions about the design methodology for modeling

3.3. Uses defined by the authors for their models: understanding versus action

3.3.1. Indirect approach: description of the objectives of the model by the author

3.3.2. Direct approach: possible uses to which authors referred to

3.3.3. Comparing the results obtained with both approaches to the use of the models

3.4. Link between the design methodologies for modelling and the use of the models

4. Conclusion

\section{Introduction}

Agriculture in the twenty-first century is complex as it must combine efficient agricultural production with environmental concerns, limited water, climate change, and global competition. Integrated and quantitative system approaches are needed to understand these complex phenomena and manage them. Models are seen as a means to support such approaches and have thus become major tools in today's agricultural research since their first appearance about 50 years ago. The history of modelling in its different forms in agricultural research has been traced by diverse authors. Initially focused on the estimation of light interception and photosynthesis (de Wit 1965), its scope has since widened and there are now many major modelling groups. An important branch is crop modelling, which is usually defined as the dynamic simulation of crop growth: see for example Sinclair and Seligman (1996). A wide variety of crop models has been developed all over the world and several have been structured into three main groups (Jones et al. 2001): in the USA with the former project International Benchmark Sites Network for Agrotechnology Transfer (IBSNAT, Uehara and Tsuji 1998) that gathers together models like CERES or DSSAT; in Australia with the system Agricultural Production system SIMulator (APSIM; McCown et al. 1996); and in The Netherlands at Wageningen with the School of de Wit (Bouman et al. 1996) including models like SUCROS,
WOFOST, or LINTUL. These groups are however only one part of the modelling community as modelling is widespread in agricultural research. Other forms of models like farm models have also been thoroughly developed and discussed, see for example Janssen and van Ittersum (2007) or McCown (2001).

To cope with the semantic diversity that agronomists give to the word "model", many classifications have been tried. One distinction that seems to be commonly accepted (though not yet clearly defined) is that between functional and mechanistic models. The first are essentially practical and are also called empirical or heuristic; the others aim to represent biological and physiological processes (Passioura 1996; Poluektov and Topaj 2001). Nonetheless, many other classifications exist, e.g., distinguishing dynamic simulation models from statistical ones (Sinclair and Seligman 2000) or using the different forms of mathematical representations and methods of analysis to characterize the models (Woodward et al. 2008). In this paper, we adopt a comprehensive stance: as long as the author claims that the paper deals with modelling issues, we will consider it whatever the modelled phenomenon or the formalism adopted to model it.

A final distinction interests us particularly, which is based on the objectives of the models. From the beginning, the models have been described as tools that help to achieve certain objectives: "research tools", "crop management tools", or "policy analysis tools" according to Boote et al. (1996), "educational tools" to Passioura (1996), "aids for interpreting experimental results, agronomic research tools or agronomic growers' tools" to Whistler et al. (1986), and "research tools" or "tools to help in the decision-making processes of practitioners" to Matthews et al. (2002). Models actually have a known heuristic value to aid the interpretation of reality, thanks to their ability to integrate understanding of processes across levels of biological organization, scales, or scientific disciplines (Hammer 1998).

However, except for their use as research tools for understanding, the use of the models for action is not well established, although it is often claimed by the authors. Matthews et al. (2002) have stated that "often in the literature, models used in research are promoted in terms of their potential to aid in decision making, although there is not always evidence that they are being used for this purpose!". Whereas the use of the models was already discussed in the symposium "Use and abuse of crop simulation models" in 1994 (see the papers of Boote et al. 1996, Monteith 1996, Passioura 1996, and Sinclair and Seligman (1996)), it has been regularly discussed since then (e.g., by Cox 1996, Hammer et al. 2002, Keating and McCown 2001, Matthews et al. 2002, McCown and Parton 2006, McCown 2001, and Woodward et al. 2008), indicating the importance of this question for the agrono- 
mist modellers. All these authors pointed out the rarity of models being used outside the field of research.

The reasons for this rarity of use have also been much debated. Cox (1996) or Parker (1999) mention a category mistake by explaining that the modellers have tried to design decision support systems from existing research models without appreciating that a gap could exist between the research models, focused on the exploration of processes, and models built for action and use. Meynard et al. (2002) draw attention to the gap between the representation on which the researchers or advisers base their recommendations and the way farmers make decisions. Lynch et al. (2000) list different factors that prevent decision support systems based on agronomic models from being adopted, and these factors may be extended to the rare adoption of the agronomic models themselves: a mismatch between the systems represented in the models and the needs of the users, techno-centered design, inadequate design and use of complex computer tools, conflicts between the use of the decision support systems and the activities of the potential users, unavailability of input data, lack of confidence in the output, and so on. Finally, many authors have pointed out the failure to consider the real work activities of the users at early design stages (Carberry et al. 2002; Hayman and Easdown 2002; Parker 2004).

Indeed, modelling to aid the understanding of reality and modelling to support action might be quite different. Modelling to aid understanding is about the integration of knowledge about biophysical processes across levels of biological organization, scales, or scientific disciplines, and is mainly driven by the acquisition of knowledge of such processes over a range of soil, weather, and cultivation situations from experimental or on-farm data. Modelling to support action refers to supporting decision-making and may be part of a design process of an operational tool: decision support systems (DSS) for instance. Thus, the objectives and also the users are fundamentally different between a modelling process oriented towards action and one oriented towards understanding. This ought to influence the structure and content of models, as agronomic models can be defined as "representations of a system" based on approximations, choices, and hypotheses necessary to cope with the complexity of the reality. The inadequacy of the representation conveyed by a model to the objective and the users of this model may be another reason for a rare use of models outside the field of research, rather than reasons of software programming or transfer.

This paper aims to show whether such a reason is widely identified by the designers of models: do they expressly link their representation of reality to the objectives they give to their models, and if so how? More particularly, when they model for action, do they design models differently than for understanding? To answer such questions while getting a broad overview of the modelling practices in agronomic research, we chose to carry out a quantitative bibliographic approach based on mainstream journals of agronomic science rather than on specialized literature about software and modelling development. Indeed, the latest mainly addresses properties of DSSs, whether or not based on agronomic models, rather than the representation of the reality involved in the model. We chose to focus on the modelling methodology as we considered it as an indirect indicator of the approximations, choices, and hypotheses made by the modeller to represent reality. We thus concentrated on the methodological steps of design described by the authors and tried to find out how they link them with the objective(s) they assign to their models.

\section{Materials and methods}

\subsection{Analyzing abstracts and full texts}

Although the surge of scientific literature has made it difficult for researchers to keep track of developments in their fields of interest, several techniques, notably in biomedical research, have been developed to extract and retrieve information from large datasets. Generally, such techniques use the abstracts of the papers, mostly due to their wide availability in the databases and because they "are assumed to contain the information most relevant to the paper, therefore having a higher information density than full text" (Schuemie et al. 2004). Such an assumption is largely reinforced in the guidelines provided by international abstracting standards, such as the American National Standard for Writing Abstracts, as well as those provided by the scientific journals. Whether it be in the guide for authors from Agricultural systems, European Journal of Agronomy, Field Crops Resarch, Crop \& Pasture Science, or Agronomy for Sustainable Development, the same definitions are used: the abstracts are supposed "to state concisely the scope of the work and give the principal findings or the main scientific breakthrough". They are supposed "to be complete enough to be able to stand alone".

As we aimed to grasp the main debates and practices of the modellers in the agronomic research community, these guidelines led us to assume that analyzing the abstracts of a large corpus of papers would give us such a view. In fact, according to the guidelines, abstracts are assumed to contain the main information the authors want to emphasize and share with the research community. Several studies have nonetheless pointed out the weaknesses of such analyses, showing that authors may fail to give the main scientific information in their abstracts (Schuemie et al. 2004; Cohen and Hersh 2005). Consequently, and to assess 
the results given by the analysis of abstracts, we decided to analyze the full-text contents of a sample of our corpus. We then chose to read thoroughly a $5 \%$ sample of the papers we collected.

\subsection{Building of the dataset}

We focused on the numerous papers describing new models or major modifications to existing models to study how their authors describe their design methodology as well as the objectives and uses proposed for the model. Eight wellknown journals dealing with agronomic research and available in the ISI Web Of Science database were chosen to run a search procedure over a 12-year period: Agricultural Systems, Agronomy Journal, Agriculture Ecosystems \& Environment, Agronomy for Sustainable Development (formerly Agronomie), Crop \& Pasture Science (formerly Australian Journal of Agricultural Research), Crop Science, European Journal of Agronomy and Field Crops Research. These journals were chosen for their ability to represent the mainstream practices in the agronomic research community of modellers. According to their aims and scope, they welcome papers about models without being specific about their type or objectives or how to structure the papers.

We decided to begin our search in 1996, as it was about then that doubts began to arise about the use of models in the previously mentioned symposium "Use and abuse of crop simulation models" held in 1994.

The search procedure was built using a list of descriptors to look for in the titles and abstracts of the papers published in these journals. It was centered on the word "model": according to the diversity of model types and the lack of a coherent and consensual classification, we decided not to predefine the types of models we would explore. As soon as an author had stated that she/he had built a model, we considered it. We thus built a request in which the word "model" and all derived words (models, modelling, modelled, etc.) had to appear in the same sentence as words belonging to the lexical field of design (like create, build, new, develop, design, etc.). The exact request submitted in the ISI Web of Science database was:

Topic $=$ model* SAME (design* OR construct* OR buil $^{*}$ OR develop* OR new* OR creat* OR modif* OR present* OR propos*).

Publication name: Agricultural Systems OR Agronomy Journal OR Agriculture Ecosystems \& Environment OR Agronomy for Sustainable Development OR Agronomie OR Australian Journal of Agricultural Research OR Crop Science OR European Journal of Agronomy OR Field Crops Research.

Timespan: From 1996 to 2008 .

Document type: Article

This request was run in 2009 .
All the abstracts of the 1,060 selected papers were read to check their relevance. We firstly selected on the type of model, retaining those dealing with crop production: we excluded models that were focused only on genetic, economic, or livestock issues unless they also included an agronomic aspect. We then eliminated the papers that did not describe the building of a new model or a major modification of an existing one. For example, those dealing only with the parameterisation or evaluation of an existing model in a new situation or use were removed. When the search retrieved one of a series of papers, we kept them all to be sure of finding the entire methodology, and counted this series as one unit of the dataset. We finally obtained a database of 518 "units" on the abstracts of which we then ran our analysis.

\subsection{Work on the 518-unit dataset of abstracts}

Our goal was, firstly, to investigate how authors describe their design methodology for modelling, and secondly, to find out whether and how they describe a future use for their models. We identified all the information given about the methodology used by reading the whole abstracts and extracting the different modelling or design steps defined by the authors. It was actually the description of the stepby-step process that the authors followed to design their models that we wanted to collect. We then compared the described steps across all the dataset units.

To reveal the future use that the authors describe for their models, we combined two approaches. We firstly extracted the objectives given by the authors for their models. In fact, the authors usually define the objectives of the model at the beginning of the abstract, introduced by sentences like "the objectives of the model was to...", "our objective/goal/aim was to model...", "the model was developed to...". All these extracts were analyzed to characterize their keywords, particularly the main verbs that were used to define the objective (e.g., for the objective "This paper develops a nonlinear, bio-economic model for analyzing the system behavior in terms of land use changes and forest degradation processes", the main verb is "analyze"). Secondly, we extracted all mentions made by the authors about the use of the models. This information, mostly given at the end of the abstracts, was located by searching for words derived from "use" (like use(s), user(s), useful, verb use...) or words like "utility", "suitable", "application", or "applied to". Having gathered these two forms of information, we analyzed the link that might exist between the intended use and the methodological issues addressed in the abstract.

\subsection{Analyzing full texts in a randomized sample of 25 papers}

To confront and strengthen the analysis of the abstracts, 25 papers were randomly extracted from the dataset and read 
in their entirety. Looking for the same elements, we searched for in the abstracts, we collected information linked with (1) the description of the design process followed by the authors by listing the different steps described in the paper, (2) the objectives given by the authors to their model(s), (3) every mention of the potential use of the models. In the last category, we also extracted mentions of the intended users of the model and their role in the design process. The results obtained from the full texts will be discussed together with those obtained on the abstracts for these three points (design process, objectives given by the authors to their models, and mention of the use of the models).

\section{Results and discussion}

In this paper, we assume that a model is a representation of reality, and that the failure of this representation to match the objective assigned to the model may explain the low use of agronomic models outside the field of research. We assume that information about the content of the models could be found by looking at the design methodology for modelling. We thus focus on the methodological steps described by the authors and search links between these steps and the objective claimed for the model. We consider mainstream agronomic science journals and perform a literature analysis in order to identify the extent to which this question has been debated within the agronomic research community. We thus analyze 518 abstracts and check the results of this analysis by also reading a sample of 25 full-text papers randomly extracted from this 518paper dataset.

\subsection{Describing elements in the 518-unit dataset}

Below, we give a few elements to characterize our dataset. The number of papers whose topic contains the word model and its derivates increased steadily, in proportion to the total number of papers, from $1975(0.6 \%)$ till the 2000s $(19.6 \%$ on average between 2000 and 2008). Our study, which begins in 1996, deals with a period during which publications about models were well established and regular. Actually, among the papers whose topic contains the world "model", a lot deal with non-agronomic models or focus on the evaluation of an existing model. This explains why the number of papers in our dataset describing new agronomic models or major modifications to existing ones in agricultural research is much lower and remains stable, from $3 \%$ to $5 \%$ of the published papers, that is to say 30-54 papers each year over the period considered.

Observing the countries of publication of our dataset shows a strong interest and contribution from the USA (134 papers), Europe (75 papers from France, 55 from UK, 48 from the Netherlands, 31 from Germany, 19 from Denmark and Spain, 18 from Italy), and Australia (60 papers) in the design of new models. This is consistent with the three major modelling groups mentioned above: a group, mainly in the USA, around IBSNAT; an Australian group around APSIM; and a Dutch group, also called the School of de Wit. However, the papers published in Europe are not confined to this school as witnessed by the strong contribution of France and the UK. In both of these countries, the communities of modellers seem to be less structured around a single and federative model, although French workgroups structured around STICS or gene flow models, e.g., GENESYS or MAPOD, can be identified.

When looking at the distribution of the selected papers by journal, it can be seen that Agricultural Systems dominates (144 papers), followed by Agriculture, Ecosystems \& Environment (83 papers), Field Crops Research (81 papers), Agronomy Journal (72 papers), and European Journal of Agronomy (60 papers). Agronomy for Sustainable Development (29 papers), Australian Journal of Agricultural Research (27 papers), and Crop Science (22 papers) are less represented in our dataset.

Table 1 gives a list of the main authors of the dataset, having contributed to at least four papers of the dataset. This list is consistent with the list of the main contributing countries with authors mainly from Australia, USA, and Europe.

3.2 A six-step design methodology shared by the agronomic research community

\subsubsection{The design methodology as described in the abstracts}

Description of the design methodology followed by the authors to build their model(s) is mainly addressed in the abstracts by naming the modelling steps which will be described in the paper. These modelling steps are homogeneous in the dataset: from one paper to another, six standard steps are most often quoted. The first, found in 513 units of the dataset, is dedicated to describing the main characteristics of the model: type of model, inputs and outputs, diverse components or submodels, main assumptions, time step, and validity domain. The second, found in 228 units, aims to define the data that were used to build the model. Depending on the paper, these data mainly come from experimental field trials, expert knowledge, surveys, or literature. In a third step, found in 205 units, the formalism of the model is described. The authors give some of the mathematical relationships linking the variables. We can then find, in 107 units, a description of calibration or parameterization processes. The authors more particularly specify the data they have used for this process by giving 
Table 1 List of the authors who contributed to at least four papers reporting either new models or improved existing models to our dataset

\begin{tabular}{|c|c|}
\hline Author & Record count \\
\hline Robertson, MJ (Australia) & 9 \\
\hline Hoogenboom, G (USA) & 9 \\
\hline Batchelor, WD (USA) & 9 \\
\hline Boote, KJ (USA) & 8 \\
\hline Meynard, JM (France) & 8 \\
\hline Westgate, ME (USA) & 8 \\
\hline Jones, JW (USA) & 7 \\
\hline Hammer, GL (Australia) & 7 \\
\hline Lizaso, JI (USA) & 7 \\
\hline Jamieson, PD (New Zealand) & 6 \\
\hline Ritchie, JT (USA) & 6 \\
\hline Van Keulen, H (Netherlands) & 6 \\
\hline Colbach, N (France) & 6 \\
\hline Horie, T (Japon) & 6 \\
\hline Carberry, PS (Australia) & 5 \\
\hline Meinke, H (Australia Netherlands) & 5 \\
\hline Asseng, S (Australia) & 5 \\
\hline Semenov, MA (UK) & 5 \\
\hline Dingkuhn, M (France) & 5 \\
\hline Stutzel, H (Germany) & 5 \\
\hline Wery, J (France) & 5 \\
\hline White, JW (USA) & 4 \\
\hline Van Ittersum, MK (Netherlands) & 4 \\
\hline Jeuffroy, MH (France) & 4 \\
\hline Kropff, MJ (Netherlands) & 4 \\
\hline Sinclair, TR (USA Australia) & 4 \\
\hline Brisson, N (France) & 4 \\
\hline Huth, NI (Australia) & 4 \\
\hline Muchow, RC (Australia) & 4 \\
\hline Olesen, JE (Denmark) & 4 \\
\hline Weiss, A (USA) & 4 \\
\hline Bergez, JE (France) & 4 \\
\hline Dobermann, A (USA) & 4 \\
\hline Milroy, SP (Australia) & 4 \\
\hline Capillon, A (France) & 4 \\
\hline Manschadi, AM (Germany) & 4 \\
\hline Orgaz, F (Spain) & 4 \\
\hline Stewart, DW (Canada) & 4 \\
\hline Veldkamp, A (Netherlands) & 4 \\
\hline Probert, ME (Australia) & 4 \\
\hline
\end{tabular}

their source, mostly field trials, literature, expert knowledge, or outputs of other models. A fifth step describing the validation of the newly designed model is found in 340 units of the dataset. Several methods are described: comparison with field data (independent or not of the data used to build the model), with literature (results from other models, field data), or with expert knowledge. This validation step may also include sensitivity analysis. Finally, a sixth step dealing with the application of the model is to be found in 228 units. In this step, the authors give some examples of the results of their models when used to address a specific question. These examples may be used to analyze some processes that are particularly important in the papers by discussing the weight of certain factors, ranking them, and diagnosing weak points or possibilities for improvement, etc. These six steps are summarized and exemplified in Table 2.

Although these six same steps are to be found throughout the dataset, they are not presented by the authors as forming an overall methodology. The six steps are hardly ever quoted in a single abstract. To go deeper into this point, we looked at the number of steps described in each unit. It averages 3.13 for the 518-paper dataset. Only two units combine the six steps, one of them by using three consecutive subpapers (van Oosterom et al. 2001a, b, 2002; Yoshida et al. 2006). In most cases, each step is discussed independently.

\subsubsection{Additional findings from the full-text analysis}

Compared with the abstracts, the full-text papers allow the authors to describe more extensively their method for designing models, but always by using the steps already mentioned in the abstracts: description, source of data, formalism, parameterization/calibration, validation, and application. Whereas the average number of steps described in the abstracts of these 25 papers was 3.18 , it was 5.0 for the full texts. Nine papers out of 25 describe the six steps. The full texts use more space to describe iterations, modifications, and improvements made to the model during its design (12 papers out of 25), which hardly ever appear in the abstracts. However, in the full texts as in the abstracts, there are very few signs that the authors give thought to design methodology for modelling or that they have a critical eye to the six steps most of them use. As in the abstracts, discussions may exist about one step or another (parameterization or validation mostly) but hardly ever about the overall design process.

\subsubsection{Conclusions about the design methodology for modelling}

We find that all the authors present the design methodology for modelling in a segmented way. The way they segment it is very standardized since each paper of our dataset refers to one or several of the six following steps to describe the design process: description step, data source step, formalism step, calibration/parameterization step, or validation step. 
Table 2 Description and illustration of six standard methodological steps characterized from a sample of 518 scientific papers reporting either new models or improved existing models

\begin{tabular}{|c|c|c|c|}
\hline & Step & Content & Examples \\
\hline 1 & $\begin{array}{l}\text { Descriptive step } \\
\text { (513 papers })\end{array}$ & $\begin{array}{l}\text { Type of model, inputs-outputs, components- } \\
\text { submodels, assumptions, time step, } \\
\text { validity domain }\end{array}$ & $\begin{array}{l}\text { In order to identify which cropping practice may be altered, depending } \\
\text { on each farm's characteristics, we built a rule-based model that } \\
\text { represents how market gardeners plan cropping cycles of lettuce and } \\
\text { endive [...] on a farm scale. The model is adapted to the specificities } \\
\text { of salad vegetable crops in the Mediterranean region, in particular } \\
\text { the combination of several cycles per year and of open field and } \\
\text { sheltered crops. The output variables are the developed areas } \\
\text { allocated to the different salad types and the range of the harvest } \\
\text { dates, which are two key factors for commercialisation } \\
\text { (Navarrete and Le Bail 2007) }\end{array}$ \\
\hline 2 & $\begin{array}{l}\text { Data source step } \\
\text { (228 papers })\end{array}$ & $\begin{array}{l}\text { field trials, literature, expert knowledge, } \\
\text { surveys }\end{array}$ & $\begin{array}{l}\text { Field experiments were carried out during 1992, } 1993 \text { and } 1994 \text { in } \\
\text { Cordoba, Spain (38 degrees N). Sunflower populations with similar } \\
\text { genetic background but with differences in early vigour were used } \\
\text { to study the association of this trait with other characters and with } \\
\text { the genetic parameters required to run the model (Aguera et al. 1997) }\end{array}$ \\
\hline 3 & $\begin{array}{l}\text { Formalism step } \\
\text { (205 papers })\end{array}$ & Mathematical relations between variables & $\begin{array}{l}\text { A phenology model was developed which utilises the beta function for } \\
\text { response to hourly air temperature, and a switch-off function for } \\
\text { response to day length. The life cycle of hemp from emergence to } \\
50 \% \text { of flowering was defined in terms of physiological development } \\
\text { days (chronological days at the optimum photoperiod and } \\
\text { temperature) } \\
\text { and considered in three phases: juvenile phase (BVP), photo-sensitive } \\
\text { phase (PIP), flower development phase (FDP; Amaducci et al. 2008) }\end{array}$ \\
\hline 4 & $\begin{array}{l}\text { Calibration- } \\
\text { parameterization } \\
\text { step }(107 \text { papers })\end{array}$ & $\begin{array}{l}\text { Source of data to calibrate / parameterize: } \\
\text { field trials, literature, expert knowledge, } \\
\text { outputs of other models }\end{array}$ & $\begin{array}{l}\text { The conversion of above ground dry biomass into crop yield has been } \\
\text { calibrated through harvest indices and the values obtained are } \\
\text { compared with the international literature (Bastiaanssen and Ali } \\
\text { 2003) }\end{array}$ \\
\hline 5 & $\begin{array}{r}\text { Validation step } \\
\text { (340 papers) }\end{array}$ & $\begin{array}{l}\text { Comparison with field data (independent or not, } \\
\text { cross-validation), with literature (other mod } \\
\text { els, data), with other designed models, with } \\
\text { expert knowledge. Use of sensitivity analysis }\end{array}$ & $\begin{array}{l}\text { Two datasets that included detailed measurements of crop production, } \\
\text { nitrogen uptake and leaf area indices from two sites were used for } \\
\text { testing. An arable organic experiment from three sites including } \\
\text { several treatments over } 4 \text { years was also used for testing. The model } \\
\text { predicted the increase in resource utilisation of pea and barley and } \\
\text { effects on pea symbiotic nitrogen fixation satisfactorily. The effects } \\
\text { of pea interspecific competition on barley production agreed with } \\
\text { observations, but the simulated effect of barley interspecific } \\
\text { competition on pea was underestimated (Berntsen et al. 2004) }\end{array}$ \\
\hline 6 & $\begin{array}{l}\text { Application step } \\
\text { (228 papers) }\end{array}$ & $\begin{array}{l}\text { Examples, factor weight (sensitivity analysis), } \\
\text { understanding of processes }\end{array}$ & $\begin{array}{l}\text { A representative farm with ten scenarios representing the range of } \\
\text { household composition was simulated. Results in 10, } 20 \text { and } \\
40 \text {-year runs showed that family composition has a large influence } \\
\text { on economic stress. Families with fewer members were economically } \\
\text { better off after 10, 20, and even } 40 \text { years. With more young or } \\
\text { very old members, the expenses and consumption requirements } \\
\text { exceeded the benefits from the additional labor, and debt was } \\
\text { greater and of longer duration. Changing prices and yields across } \\
\text { their observed ranged of variability influenced simulated financial } \\
\text { position, but not the ranking of results among household } \\
\text { composition scenarios (Cabrera et al. 2005) }\end{array}$ \\
\hline
\end{tabular}

These steps stand for the information given by the authors about their design methodology for modelling

Moreover, whereas some details can sometimes be given in the full texts about the design process (like the iterations, modifications, or improvements the designers make while building their model), such issues are not pointed out in the abstracts, where one expects to find the most relevant scientific questions dealt with by the authors. This suggests that methodological issues regarding the whole modelling design process are not regarded as a research topic which can be addressed in papers dealing with the building of agronomic models. Moreover, it suggests that this methodological question is not considered important in mainstream agronomy, whereas the question of model usability is. Finally, reading the abstracts and full texts in search of methodological debates about model design indicates that there is a standard and 
uniform way to describe the building of a model, founded on standard steps established as early as the 1970s. It is interesting to note that no author refers to well-attested design methods for software developers and designers like waterfall models, spiral models, iterative, or agile development models. On the contrary, the six steps discussed above match those described in the main founding work on agronomic modelling from de Wit (1978), Penning de Vries et al. (1989), Hanks and Ritchie (1991), Bonhomme (1997), Peart and Curry (1998), or Jones and Luyten (1998). It would however be interesting to ask to what extent this standardization is due to publication protocol. It is indeed doubtful that every author uses exactly the same way to build a model. It may be assumed that these common ways of describing modelling methods do not leave much room for scientific debate and thinking about the design methodology for modelling.

3.3 Uses defined by the authors for their models: understanding versus action

Two approaches were combined to identify the use the authors imagine for their models: (1) extracting the objectives given by the authors for their models and (2) extracting all direct mentions made by the authors about the use of the models.

\subsubsection{Indirect approach: description of the objectives of the model by the authors}

The analysis of the abstracts shows that 491 units out of 518 include some elements defining the objectives the authors give for their models. To analyze these elements and assess what they reveal in terms of use of the model, we focused on the words, and mainly verbs, used by the authors to qualify the work they want to do on the agronomic subject tackled .Two categories of verbs can be identified. First, the main verbs refer to a lexical field of exploration and understanding. They include all the verbs describing an analysis of agronomic processes, whatever the process considered: reaching potential yield, analyzing optimal nutrient management, assessing the impacts of climate change, describing land use changes, etc. We find, in this first category, the following verbs: characterize, explore, understand, estimate, predict, quantify, define, explain, and investigate. Secondly, we find words belonging to the lexical field of use, showing that the models are linked to action or decision: support, manage, assist, tool, decision and decision-making, help, and enable. As shown in Table 3, in spite of a wide diversity of scopes (e.g., ecophysiology, farming systems management, and land use), the models in our dataset mainly target exploration and understanding ( $88.8 \%$ of 518 units). This is confirmed by the analysis of the 25 full-text sample: the objectives given in the abstract and in the full texts (mostly as soon as the introduction) are consistent and are mainly oriented toward understanding (22 papers out of $25,88.0 \%)$. This result is consistent with the assumptions of Boote et al. (1996) or Cox (1996) according to whom agronomic models are above all tools for researchers to understand and describe complex processes.

\subsubsection{Direct approach: possible uses which the authors refer to}

If we now look at the way the authors simply mention a use for their models, it appears that $51.5 \%$ of them define an explicit use for their models in their abstracts (267 units out of 518). The defined uses can be placed in four categories (shown in Table 4): a research one which is predominant (123 units out of $518,23.7 \%$ ); a use to design and assess policies (23 papers, 4.4\%): a use for crop managers, advisors, or crop firms (78 papers, 15.1\%); and other uses not clearly defined (61 papers, $11.8 \%$ ). Some papers define several uses that can be assigned to different categories, which explains why the sum of the number of units by categories exceeds 267 .

The analysis of the 25 full-text sample shows that use issues are sometimes addressed in the paper but not mentioned in the abstract. Actually, every paper in the

Table 3 The two categories of model objectives expressed by their authors in the abstracts the 518-paper dataset (in 27 papers, authors make no mention of an objective of their model)

Main objective of the model Designing models to explore and understand Designing models linked to action or decision

Keyword (expressions used to define the objective of the model)

Number of papers (out of 491 where the objective of the model is clearly stated)
Characterize, estimate, simulate (effects), quantify, define, explain, analyze, develop, maximize, perform comparisons, diagnose, find a combination, establish, identify, investigate
Support, manage, assist, tool, feasible, decision, help, make recommendation

In spite of a large diversity of scopes, $93.6 \%$ of models in our dataset target exploration and understanding and only $6.4 \%$ initially aim to support decision or action 
Table 4 Classification of the papers of the dataset through direct mention of use of the models

\begin{tabular}{ll}
\hline Category of use & No of papers \\
\hline Research use & $\begin{array}{c}123(23.7 \% \text { of the } 518 \text {-paper dataset, } \\
46.1 \% \text { of the } 267 \text { papers naming a use })\end{array}$
\end{tabular}

Examples

Use to design and assess policies
$23(4.4 \%$ of $518,8.6 \%$ of 267$)$

$78(15.1 \%$ of $51829.2 \%$ of 267$)$ advisors or crop firms se for crop managers

"The model has potential use in future studies to relate windbreak effects to crop yield and to evaluate windbreak designs for maximum benefits" (Zhang and Brandle 1996)

"This model could be used as an easy and inexpensive means for detection of the structural and functional state of photosynthetic membranes in wheat and maize, and possibly other crops, in hot environments" (Ristic et al. 2008)

"We illustrate the strength of empirical multi-agent models with simulation results from Uganda and Chile and indicate how they may assist policymakers in prioritizing and targeting alternative policy interventions especially in less-favoured areas" (Berger et al. 2006)

"The results show the usefulness of this methodological approach to evaluate the impact of policies and highlight the fact that water pricing and agricultural policy need to be closely coordinated in order to meet the EU's policy objectives for the irrigated agriculture sector" (Riesgo and Gomez-Limon 2006)

"Hence the agricultural planner can use the outputs of SAWAS in order to bridge the gap between the limited water resources and the increased agricultural production in an area that suffers from severe water scarcity" (Salman et al. 2001)

"The model uses only one cultivar-dependent parameter (mean weight per seed), and thus it can be easily used by farmers or advisers for practical purposes such as agronomic diagnosis to explain the lack of seeds on some nodes" (Roche and Jeuffroy 2000)

Non directed use $\quad 61(11.8 \%$ of $51822.8 \%$ of 267$)$

No mention of use

$251(48.5 \%$ of 518$)$
"The proposed SOYDEV model may be particularly suitable for practical model applications because of its reduced need for cultivar-specific calibration" (Setiyono et al. 2007)

"The results are also compared with experimental results in order to evaluate the usefulness of this model: with conventional measurements under field conditions, the prediction of water balance evolution is rather consistent with experimental results" (Personne et al. 2003)

$51.5 \%$ of dataset papers explicitly mention a use of the models. When considering these papers (267 papers), $46.1 \%$ of papers name a research use, $37.8 \%$ intend to support action and decision, and $22.8 \%$ of papers name nondirected uses

sample includes one or several mentions of use of the models, whereas they were not always mentioned in the abstracts ( 8 papers out of the 25 of our sample made no mention of use in the abstracts). Moreover, several full papers cite several categories of use (e.g., seven papers quote two categories of users - research and crop management, or policy design and crop management notably). Nonetheless, these mentions are mostly made in the introduction and/or discussion and conclusion parts of the papers and presented as future developments or possibilities for the models subject to modification. For example, Alary et al. (2007) explain that "The results show that a dynamic mathematical model could be used as an ex post impact assessment tool, but important features must be improved"; Bacsi (1997) states that "it is true that, due to the extreme sensitivity to initial conditions and parameter values, the chaotic models cannot easily be used for predictions but, instead, they have a great advantage: they can identify the parameter ranges where the process modelled is unstable. This way, chaotic models can direct the attempts made at stabilization by describing clearly which is the parameter range the decision makers have to avoid in order to reach a stable and regular behaviour"; and Cabelguenne et al. (1999) affirm that "[the model is] preliminary to the production of a multi year agronomic model which can be used both as an exploratory tool and a decision aid". If use is present, it remains mostly a possible prospect.

\subsubsection{Comparing the results obtained with both approaches} to the use of the models

Combining both our approaches to the use of the models (through the objectives given by the authors to their models and through direct mentions of use of the models) reveals interesting differences, particularly when analyzing the abstracts of the dataset (Fig. 1). Firstly, it can be seen that 
Indirect approach: how are the objectives of the model described?

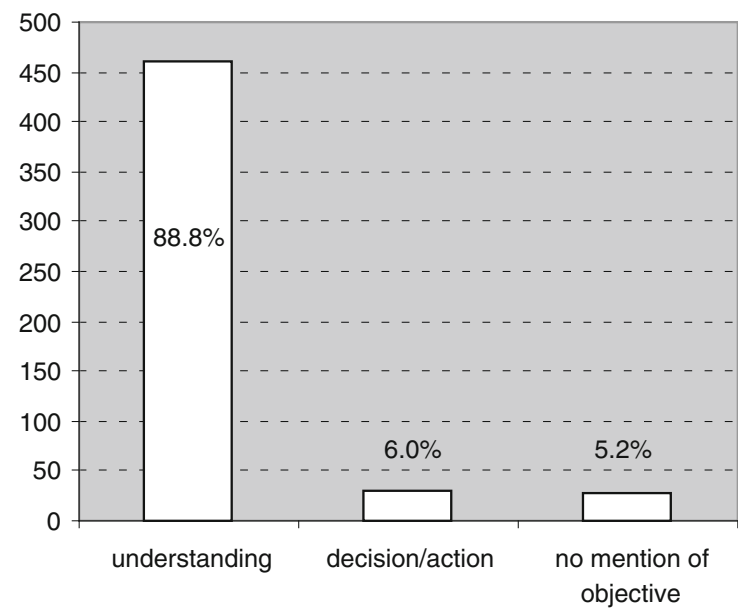

Fig. 1 Comparing two approaches to identify the use intended by the authors for their models in the abstracts of our 518-paper dataset. Whereas $88.8 \%$ of authors claim in their abstracts that the major objective of their models is to improve understanding as opposed to

all the units in which we did not find any mention of a use for the models deal with models whose authors said that they were developed for understanding. Conversely, in all the units in which the authors define an objective linked to action or decision (31 papers, see above) we find mention of a use. But contradictions may appear between the mentioned objective and the mentioned use. Indeed, $19.5 \%$ of the units in the whole dataset mention a use other than research (101 units out of 518, distributed among 78 for use by crop managers, crop firms or advisors, and 23 to design and assess policy) while only $6 \%$ of the units mentioned an objective other than understanding. More precisely, for these 101 units mentioning a use other than research, 77 express an objective of understanding. As an illustration, Zhang et al. (2005) express the following objective for their model: "model the relative abundance of five functional groups of plant species". They also finish with the sentence "The integration of the decision tree with GIS [Geographic Information System] in this study provides a platform to investigate community structure and functional composition for a pasture over space, and thus can be applied as a tool in pasture management". The initial objective of understanding is thus extended to use the model as a tool in pasture management. This phenomenon is very much confirmed when analyzing the full-text contents: whatever objective they define for their models, most of the authors will discuss or conclude their papers by mentioning a possible practical application as crop management or policy design or assessment.

In the following part, we will combine the results about design methodologies and use of the model to come back to the main questions of our paper: do the designers of the
Direct approach: what possible uses are referred to?

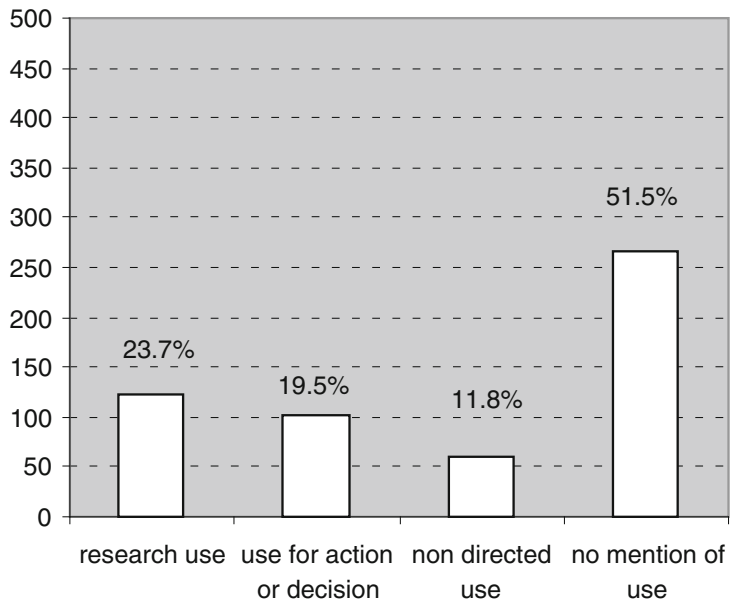

support action, $19.5 \%$ of authors also quote a possible use of their models outside research. The initial objective of understanding is thus extended to use the models as tools for action

models expressly link the design of their representation of reality to the objectives they give to their models and how? More particularly, when they model for action, do they design models differently from those intended for understanding?

3.4 Link between the design methodologies for modelling and the use of the models

This bibliographic analysis aimed at finding out whether agronomic modellers make any connection between the methodology they use in building their models, as a way of developing the content of the models, and the use they envisage for them.

Firstly, we should recall that the authors of the papers included in our analysis share a standardized methodology: the same methodological steps are mentioned by nearly all of them. As the objectives that the authors gave for their models belong to the lexical field of "understanding", we can assume that the six standard step methodology has proven to be efficient for designing tools to support research in developing a better understanding of the phenomenon they study. We can also assume that acknowledging such steps became an efficient way to communicate about the design methodology for such tools. Nonetheless, as we stated several times in our analysis, these conclusions are above all the results from a quantitative view of papers, since methodological discussion about the design process for modelling, as a specific subject, is absent from the papers.

Secondly, our analysis shows that there is little room for discussion about the need to adapt the methodology to the intended use of the model. Indeed, there is no clear 
evidence that the authors who mention an objective referring explicitly to a use outside the research community adapt their methodology to this use: they seem to stick to the standardized steps which we assume to be those which are relevant to design a research model. Out of these 101 papers identifying a use outside the field of research, only three claim some original aspects of their design methods in the abstracts. Cox (1996) who describes the SIRATAC case explains that "This escalation of commitment has had substantial implications for the design and implementation of both modelling and DSS projects". Girard and Hubert (1999) assume that "Formalising the knowledge to be used in gaining this understanding is therefore of crucial importance in building such tools". Higgins et al. (2004) explain that "Research scientists engaged in participatory research with 3 casestudy mill regions to construct the models needed to produce these optimised harvest schedules".

The analysis of the 25 full texts contributes some interesting additional aspects. It firstly confirms that defining the use of the model is not a central point for most papers: it is rarely quoted as a guiding principle for the design of the model. This aspect seems to arise as an afterthought and is skipped over by the authors in the papers of our dataset: use, however, appears to be a mandatory element to be included. Nonetheless, comments made by some authors show that the question of linking the form and structure of the model with the use intended for it is not ignored. We quote three examples coming from our 25paper sample. In the paragraph of her paper focusing on the model structure, Greiner (1998) states that "the model is an abstraction from the complex system, capturing the essential features of system behaviour. The level of abstraction depends on the purpose of the model and is critically determined by data availability and exogenous constraints". She also develops the idea that "for an applied systems analysis to secure acceptance and implementation of the research results, the model must also be able to reflect the perspective of key decision makers". Another example is the link authors create between the complexity of the model and its intended use. Herve et al. (2002) write that "exact correspondence between every real and simulated task is not necessary; rather we need a reliable model to test our understanding of farm operating and to simulate emerging dynamics in land use, such as a reduction in fallowing" or that "As in any realistic model, the object-oriented approach is concerned with accurately representing the underlying processes in a specific system, rather than with precisely matching quantitative behaviour or being generally applicable". Bindi et al. (1999) assume that "[their model] may not represent an inherent physiological regulation [...] but does provide a convenient and stable normalization for describing seed growth". Such quotations prove that linking a model's form and structure with its use is relevant, at least to address validation questions as done by these authors. We can thus question why use issues are not really addressed as key issues which can modify the design methodology for modelling.

Carberry et al. (2002), Hayman and Easdown (2002), or Parker (2004) whose work we quoted in our introduction suggest linking model form and structure with use by involving the targeted users in the design of the model. It is also consistent with research about software development or design sciences, in which participatory design is much discussed and used. Indeed, a whole stream of design methods has been developed, such as use- and user-centered methods (see for example http://www.upassoc.org/usability resources/about_usability/what_is_ucd.html), participatory design (e.g., Kensing and Blomberg 1998) and discussion about effective design methods is at the core of the design research community, as pointed out by Dorst (2008).

We thus identified the units in which people other than researchers were explicitly involved in the design of the models. Indeed, we assumed that participatory methods were more specifically used to build models linked with action or decision. From the abstracts, 30 units out of 518 mention such an involvement of nonresearchers in the design of the models. When we focused on their role in the design process for modelling as mentioned in the abstracts, we observed that they were mainly presented as sources of information to build the formalisms of the models, to parameterise the models (e.g., Colbach et al. 2001), or to validate them (e.g., Tixier et al. 2008). In only seven cases, the nonresearchers are presented as involved in the whole design process (e.g., Debaeke and Estragnat 2003; Fountas et al. 2006; Rapidel et al. 2006). However, among these 30 papers, only 9 mention a use of the models outside the field of research, the others being papers in which the objectives or the primary uses of the models are directed towards research and understanding. This means that such methods involving nonresearchers do not focus on involving potential users in the design of the models and the definition of their form and structure but rather in acquiring some expert knowledge.

In line with the quotations made above from Greiner (1998), Herve et al. (2002), or Bindi et al. (1999), we would rather propose a methodology which firstly includes an analysis of the users' decisions and activities the model is supposed to assist or support (for example, how much precision is needed to make a certain decision, or which entity is concerned by the decision, which appears not always to be the one simulated by the model) and, when possible, which also invites the users to test and discuss preliminary versions (prototypes) of the models. It would allow them to define the relevant properties of the phenomenon and of the outputs that need to be included in the model so that it could offer new insights to them in order to improve their decision or activity. We already 
developed these ideas in several papers or books (Cerf and Meynard 2006; Jeuffroy 2009; Lecomte et al. 2010; Taverne and Cerf 2009) but we suggest that they deserve to be more discussed and tested by all the community of agricultural researchers and agronomists.

\section{Conclusion}

Our literature analysis of papers reporting either new models or improved existing models shows that there is little scientific debate about the design methodology considered as a whole and even less about the link with the intended use of the models being designed. This would suggest that this topic is not considered as central within the agronomic research community, even though the community often questions the lack of use of models. This does not mean that agronomic modellers fail to innovate in their design methods. Rather it means that they do not consider it as a question requiring discussion, at least not in general agronomy journals. This lack of scientific debate about design methodologies for agronomic modelling might impede the ability of the modellers to make a better impact with their models in terms of use outside the research field (and more precisely, by people other than their designers). Therefore, we suggest that such debate should take place within the agronomic community. More specifically, we suggest that it should be focused on the link that may exist between the intended use of the models and their design, and propose to put more effort into participatory methodologies. Chosen for their experience in agriculture and other industries, the intended users of the model could take part in an analysis of the decisions and activities the model aims to support and/or by testing the models to adapt them to what they are supposed to do. This process is often pointed up in the design sciences as a factor in the successful adoption of the object being designed. This discussion is seen as a way for agronomic modelling to gain power and influence in the complex context of today's agriculture that, more than ever, could use the integrative and systemic properties of the models.

Acknowledgments We are grateful for the financial support from the FSOV (Fonds de soutien à l'obtention végétale-French fund for plant breeding). We thank Dr. Marc Barbier for his methodological help about quantitative bibliography and Alan Scaife for correcting the English language. We thank our colleagues of the research unit SenS (INRA UR 1326) for their valuable comments.

\section{References}

Aguera, F., Villalobos, F., Orgaz, F., 1997. Evaluation of sunflower (Helianthus annuus, L.) genotypes differing in early vigour using a simulation model. Eur. J. Agron. 7, 109-118.
Alary, V., Nefzaoui, A., Ben Jemaa, M., 2007. Promoting the adoption of natural resource management technology in arid and semi-arid areas: modelling the impact of spineless cactus in alley cropping in Central Tunisia. Agric. Syst. 94, 573.

Amaducci, S., Colauzzi, M., Bellocchi, G., Venturi, G., 2008. Modelling post-emergent hemp phenology (Cannabis sativa L.): theory and evaluation. Eur. J. Agron. 28, 90-102.

Bacsi, Z., 1997. Modelling chaotic behaviour in agricultural prices using a discrete deterministic nonlinear price model. Agric. Syst. 55,445 .

Bastiaanssen, W., Ali, S., 2003. A new crop yield forecasting model based on satellite measurements applied across the Indus Basin, Pakistan. Agric. Ecosyst. Environ. 94, 321-340.

Berger, T., Schreinemachers, P., Woelcke, J., 2006. Multi-agent simulation for the targeting of development policies in lessfavored areas. Agric. Syst. 88, 28-43.

Berntsen, J., Hauggard-Nielsen, H., Olesen, J., Petersen, B., Jensen, E., Thomsen, A., 2004. Modelling dry matter production and resource use in intercrops of pea and barley. Field Crops Res. 88, 69-83.

Bindi, M., Sinclair, T.R., Harrison, J., 1999. Analysis of seed growth by linear increase in harvest index. Crop Sci. 39, 486.

Bonhomme, R., 1997. Modélisation du fonctionnement d'une culture: caractérisation de la contrainte hydrique et prise en compte de ses effets. In: L'eau dans l'espace rural. Paris: INRA. pp. $85-100$.

Boote, K., Jones, J., Pickering, N., 1996. Potential uses and limitations of crop models. Agron. J. 88, 704-716.

Bouman, B., vanKeulen, H., vanLaar, H., Rabbinge, R., 1996. The 'School of de Wit' crop growth simulation models: a pedigree and historical overview. Agric. Syst. 52, 171-198.

Cabelguenne, M., Debaeke, P., Bouniols, A., 1999. EPICphase, a version of the EPIC model simulating the effects of water and nitrogen stress on biomass and yield, taking account of developmental stages: validation on maize, sunflower, sorghum, soybean and winter wheat. Agric. Syst. 60, 175.

Cabrera, V., Hildebrand, P., Jones, J., 2005. Modelling the effect of household composition on the welfare of limited-resource farmers in Coastal Canete, Peru. Agric. Syst. 86, 207-222.

Carberry, P., Hochman, Z., McCown, R., Dalguiesh, N., Foale, M., Poulton, P., Hargeaves, J., Hargreaves, D., Cawthray, S., Hillcoat, N., Robertson, M., 2002. The FARMSCAPE approach to deicsion support: farmers', advisers', researchers' monitoring, simulation, communication and performance evaluation. Agric. Syst. 74, 141-177.

Cerf, M., Meynard, JM., 2006. Les outils de pilotage des cultures: diversité de leurs usages et enseignements pour leur conception. Natures Sciences Sociétés. 14, 19-29.

Cohen, A.M., Hersh, W.R., 2005. A survey of current work in biomedical text mining. Briefings in Bioinformatics 6, 57-71.

Colbach N, Clermont-Dauphin C, Meynard J (2001) GENESYS: a model of the influence of cropping system on gene escape from herbicide tolerant rapeseed crops to rape volunteers - I. Temporal evolution of a population of rapeseed volunteers in a field. Agri Ecosys Environ 83:235

Cox, P., 1996. Some issues in the design of agricultural decision support systems. Agric. Syst. 52, 355-381.

de Wit C (1965) Photosynthesis of leaf canopies. In: Agricultural Research Report 663. Wageningen, PUDOC, p 57

de Wit, C., 1978. Introduction. In: Simulation of assimilation, respiration and transpiration of crops. Wageningen: Centre for Agricultural Publishing and Documentation. pp. 1-5.

Debaeke, P., Estragnat, A., 2003. A simple model to interpret the effects of sunflower crop management on the occurrence and severity of a major fungal disease: phomopsis stem canker. Field Crops Res. 83, 139-155. 
Dorst, K., 2008. Design research: a revolution-waiting-to-happen. Design Studies 29, 4-11.

Fountas, S., Wulfsohn, D., Blackmore, B., Jacobsen, H., Pedersen, S., 2006. A model of decision-making and information flows for information-intensive agriculture. Agric. Syst. 87, 192-210.

Girard, N., Hubert, B., 1999. Modelling expert knowledge with knowledge-based systems to design decision aids - the example of a knowledge-based model on grazing management. Agric. Syst. 59, 123-144.

Greiner, R., 1998. Catchment management for dryland salinity control: model analysis for the Liverpool plains in New South Wales. Agric. Syst. 56, 225.

Hammer, G., 1998. Crop modelling: current status and opportunities to advance. Acta Hortic. 456, 27-36.

Hammer, G., Kropff, M., Sinclair, T., Porter, J., 2002. Future contributions of crop modelling-from heuristics and supporting decision making to understanding genetic regulation and aiding crop improvement. Eur. J. Agron. 18, 15-31.

Hanks, R., Ritchie, J., 1991. Introduction. In: modeling plant and soil systems, Agronomy Monograph $\mathrm{n}^{\circ} 31$. Madison, WI: ASA, CSSA and SSSA. pp. 1-3.

Hayman, P., Easdown, W., 2002. An ecology of a DSS: reflections on managing wheat crops in the northeastern Australian grains region with WHEATMAN. Agric. Syst. 74, 57-77.

Herve, D., Genin, D., Migueis, J., 2002. A modelling approach for analysis of agro pastoral activity at the one-farm level. Agric. Syst. 71, 187.

Higgins, A., Haynes, M., Muchow, R., Prestwidge, D., 2004. Developing and implementing optimised sugarcane harvest schedules through participatory research. Aust. J. Agric. Res. 55, 297-306.

Janssen, S., van Ittersum, M., 2007. Assessing farm innovations and responses to policies: a review of bio-economic farm models. Agric. Syst 94, 622-636.

Jeuffroy, MH., 2009. Dynamiques partenariales dans une démarche de modélisation. In: Béguin P, Cerf M (Eds) Dynamique des savoirs, Dynamiques des changements. Octarès Editions, Toulouse (France), pp 191-208.

Jones, J., Luyten, J., 1998. Simulation of biological processes. In: agricultural systems modeling and simulation. New York: Marcel Dekker. pp. 19-62.

Jones, J., Keating, B., Porter, C., 2001. Approaches to modular model development. Agric. Syst. 70, 421-443.

Keating, B., McCown, R., 2001. Advances in farming systems analysis and intervention. Agric. Syst. 70, 555-579.

Kensing, F., Blomberg, J., 1998. Participatory design: issues and concerns. Comp Supp Coop Work 7, 167-185.

Lecomte, C., Prost, L., Cerf, M., Meynard, JM., 2010. Basis for designing a tool to evaluate new cultivars. Agron. Sustain. Dev. 30, 667-677.

Lynch, T., Gregor, S., Midmore, D., 2000. Intelligent support systems in agriculture: how can we do better? Aust. J. Agric. Res. 40, 609-620.

Matthews, R., Stephens, W., Hess, T., Middleton, T., Graves, A., 2002. Applications of crop/soil simulation models in tropical agricultural systems. Advances in Agronomy 76, 31-124.

McCown, R.L., 2001. Learning to bridge the gap between sciencebased decision support and the practice of farming: evolution in paradigms of model-based research and intervention form design to dialogue. Aust. J. Agric. Res. 52, 549-571.

McCown, R., Parton, K., 2006. Learning from the historical failure of farm management models to aid management practices. Part 2. Three systems approaches. Aust. J. Agric. Res. 57, 157-172.

McCown, R., Hammer, G., Hargreaves, J., Holzworth, D., Freebairn, D., 1996. APSIM: A novel software system for model development, model testing and simulation in agricultural systems research. Agric. Syst. 50, 255-271.
Meynard, J., Cerf, M., Guichard, L., Jeuffroy, M., Makowski, D., 2002. Which decision support tools for the environmental management of nitrogen? AGRONOMIE 22, 817-829.

Monteith, J., 1996. The quest for balance in crop modeling. Agron. J. $88,695-697$.

Navarrete, M., Le Bail, M., 2007. SALADPLAN: a model of the decision-making process in lettuce and endive cropping. Agron. Sustain. Dev. 27, 209-221.

Parker, C., 1999. Decision support systems: lessons from past failures. Farm Management 10, 273-289.

Parker, C., 2004. Decision support tools: barriers to uptake and use. Aspects of Applied Biology 72, 31-41.

Passioura, J., 1996. Simulation models: science; snake oil, education, or engineering? Agron. J. 88, 690-694.

Peart, R., Curry, R., 1998. Preface. In: Agricultural systems modeling and simulation. New York: Marcel Dekker. pp. iii-viii.

Penning de Vries, F., Jansen, D., ten Berge, H., Bakema, A., 1989. Introduction to crop growth modelling. In: Simulation of ecophysiological processes of growth in several annual crops. Wageningen: PUDOC. pp. 1-25.

Personne, E., Perrier, A., Tuzet, A., 2003. Simulating water uptake in the root zone with a microscopic-scale model of root extraction. Agronomie 23, 153-168.

Poluektov, R., Topaj, A., 2001. Crop modeling: nostalgia about present or reminiscence about future. Agron. J. 93, 653-659.

Rapidel, B., Defeche, C., Traore, B., Lancon, J., Wery, J., 2006. In-field development of a conceptual crop functioning and management model: a case study on cotton in southern Mali. Eur. J. Agron. 24, 304-315.

Riesgo, L., Gomez-Limon, J., 2006. Multi-criteria policy scenario analysis for public regulation of irrigated agriculture. Agric. Syst. 91, 1-28.

Ristic, Z., Bukovnik, U., Prasad, P., West, M., 2008. A model for prediction of heat stability of photosynthetic membranes. Crop Sci. 48, 1513-1522.

Roche, R., Jeuffroy, M., 2000. A model to calculate the vertical distribution of grain number in pea. Agron. J. 92, 663-671.

Salman, A., Al-Karablieh, E., Fisher, F., 2001. An inter-seasonal agricultural water allocation system (SAWAS). Agric. Syst. 68, 233-252.

Schuemie, M.J., Weeber, M., Schijvenaars, B.J.A., van Mulligen, E. M., van der Eijk, C.C., Jelier, R., Mons, B., Kors, J.A., 2004. Distribution of information in biomedical abstracts and full-text publications. Bioinformatics 20, 2597-2604.

Setiyono, T., Weiss, A., Specht, J., Bastidas, A., Cassman, K., Dobermann, A., 2007. Understanding and modeling the effect of temperature and daylength on soybean phenology under highyield conditions. Field Crops Res. 100, 257-271.

Sinclair, T., Seligman, N., 1996. Crop modeling: from infancy to maturity. Agron. J. 88, 698-704.

Sinclair, T., Seligman, N., 2000. Criteria for publishing papers on crop modeling. Field Crops Research 68, 165-172.

Taverne, M., Cerf, M., 2009. Anticiper l'usage dans un projet de conception d'un outil d'aide à la décision pour lutter contre le sclerotinia du Colza : quelles interactions entre utilisateurs et concepteurs et comment évaluer leurs apports ? In: Hubert B, de Turckheim E, Messean A (Eds) Concevoir et construire la décision : démarches en agriculture, agro-alimentaire, et espace rural. Paris : Editions QUAE.

Tixier, P., Malezieux, E., Dorel, M., Wery, J., 2008. SIMBA, a model for designing sustainable banana-based cropping systems. Agric. Syst. $97,139-150$.

Uehara, G., Tsuji, G., 1998. Overview of IBSNAT. In: Tsuji, G, Hoogenboom, G, Thornton, P (eds.). Understanding options for agricultural production. Dordrecht, the Netherlands: Kluwer Academic Publisher. pp. 1-7. 
van Oosterom, E., Carberry, P., Hargreaves, J., O'Leary, G., 2001a. Simulating growth, development, and yield of tillering pearl millet II. Simulation of canopy development. Field Crops Res. 72, 67-91.

van Oosterom, E., Carberry, P., O'Leary, G., 2001b. Simulating growth, development, and yield of tillering pearl millet I. Leaf area profiles on main shoots and tillers. Field Crops Res. 72, 51-66.

van Oosterom, E., O'Leary, G., Carberry, P., Craufurd, P., 2002. Simulating growth, development, and yield of tillering pearl millet. III. Biomass accumulation and partitioning. Field Crops Res. 79, 85-106.

Whistler, F., Acock, B., Baker, D., Fye, R., Hodges, H., Lambert, J., Lemmon, H., mcKinion, J., Reddy, V., 1986. Crop simulation models in agronomic systems. Adv. Agron. 40, 142-208.
Woodward, S., Romera, A., Beskow, W., Lovatt, S., 2008. Better simulation modelling to support farming systems innovation: review and synthesis. New Zealand Journal of Agricultural Research 51, 235-252.

Yoshida, H., Horie, T., Shiraiwa, T., 2006. A model explaining genotypic and environmental variation of rice spikelet number per unit area measured by cross-locational experiments in Asia. Field Crops Res. 97, 337-343.

Zhang, H., Brandle, J., 1996. Windbreak effect on biomass and grain mass accumulation of corn: a modeling approach. Agron. J. 88, 607-613.

Zhang, B., Valentine, I., Kemp, P., 2005. A decision tree approach modelling functional group abundance in a pasture ecosystem. Agric. Ecosyst. Environ. 110, 279-288. 